\title{
VARIA \\ UN RETABLO TOLEDANO EN EL MUSEO DE ARTE DE LA DUKE UNIVERSITY DE DURHAM (USA)
}

En el museo de Arte de la Duke University, Durham, Carolina del Norte, existe un retablo, cuyas fotografías me fueron enviadas por indicación del profesor Sullivan, de la universidad de Nueva York. Las seis tablas de que consta el retablo proceden de la colección del Dr. Paul J. Payne y las medidas de cada una de ellas -con ligeras variantes- son, $634 / 10 \times 413 / 10 \mathrm{~cm}$. El retablo está delicado a la Vida de Cristo (figs. 1-6).

Aunque el tardío influjo de Correa se evidencia en el rompimiento de Gloria de la escena de la Adoración de los Pastores, aquel es ya lejano. Las figuras son más expresivas que bellas con un sentido miguelangelesco en sus actitudes, a veces "envolventes» en sí mismas, que sólo nos atrevemos a comparar, en Toledo, con Machuca y muy concretamente con la Virgen del Sufragio, del museo del Prado. Los personajes, de amplias frentes, rostros menudos y ojos grandes enmarcados por cejas finas y curvadas -en muchos casos excesivamente soñadores- nos traen a la memoria modelos de Leyden. De otro lado la representación de medias figuras, el interés por el naturalismo y el modelo del sombrero que lleva el pastor de la escena arriba citada, nos habla de un precursor o un contemporáneo de Orrente, pero, de un modo u otro se trata de un pintor de la última etapa del siglo xvi conectado con los comienzos de la centuria siguiente, de los que los archivos aportan nombres, pero, no existen obras atribuidas ni documentadas ${ }^{1}$.

La Primera escena del retablo está dedicada a la Adoración de los pastores (fig. 1). Como fondo una rudimentaria arquitectura renacentista, de inspiración serliana en la zona baja, cortada en la parte superior por un rompimiento de gloria, con ángeles músicos, todavía muy influido por las composiciones toledanas de mediados de siglo. Aparece en primer plano una figura, cortada un poco más abajo de la cintura, mostrando unas perdices arracimadas -a lo Loarte y Sánchez Cotán- y que se descubre al modo de Bassano y Orrente con un modelo de sombrero semejante al que aparece en el Nacimiento de la parroquia de Yeste (Toledo), de este último. El otro pastor, con un cesto de mimbre con huevos y, los más lejanos con instrumentos musicales. Aunque la escena, en general, no muestra ningún efecto de interés por el claroscuro si es evidente cómo se resalta el pañal del Niño con halo luminoso como en Orrante ${ }^{2}$.

1 F. Marias: «Maestros de la catedral, artistas y artesanos». Archivo Español de Arte, 1981 (I), 1983 (II). Díaz Padrón: "Miscelánea de pintura española". Archivo Español de Arte, 1983. I. Mateo Gómez: Juan Correa Vivar. Madrid, 1983, El Toledo de El Greco (cap. La pintura toledana de mediados del siglo Xv1). Toledo, 1982.

2 Angulo y Pérez Sánchez: La pintura toledana de la primera mitad del siglo vil. Madrid, 1972. 

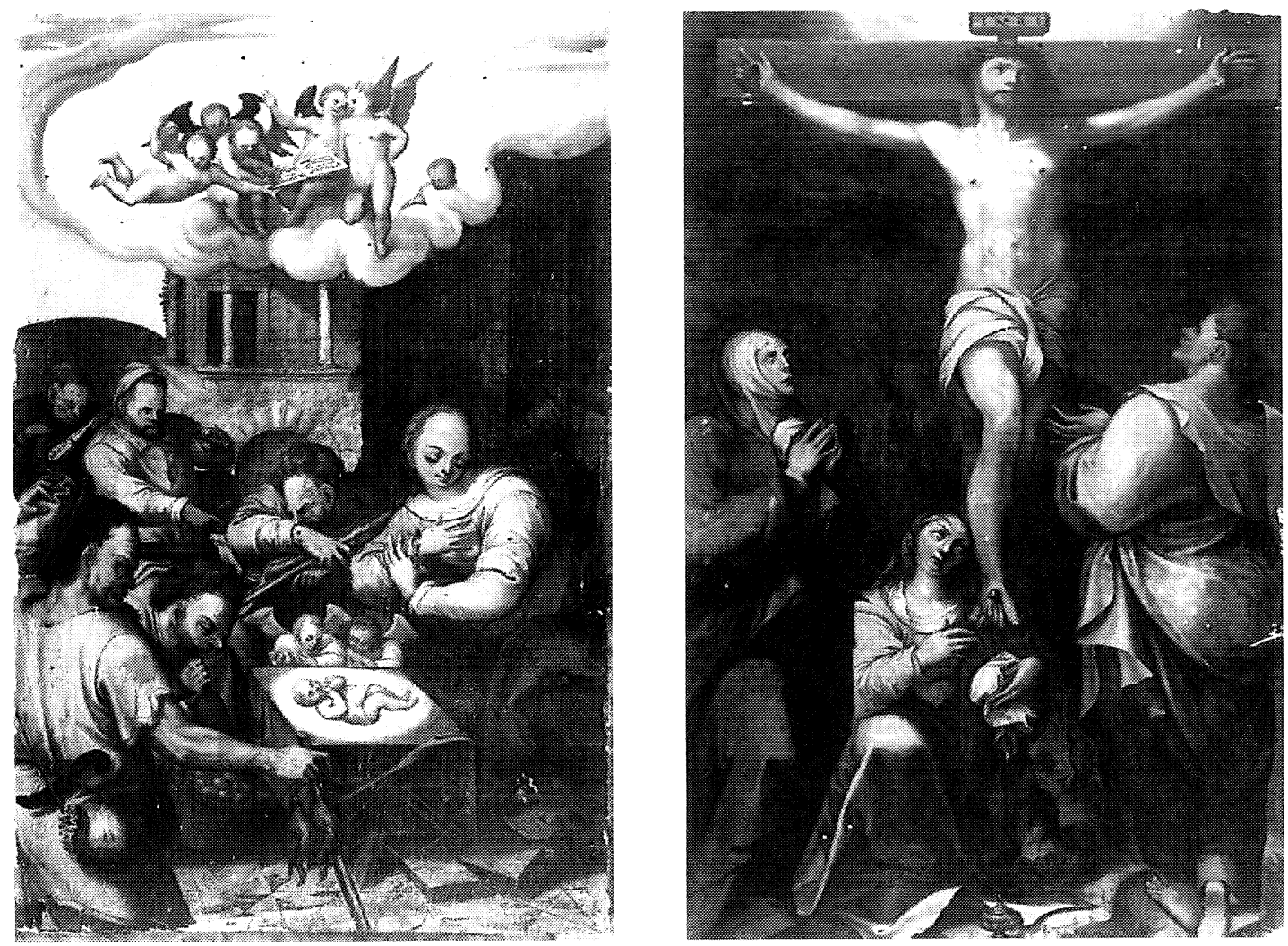

1
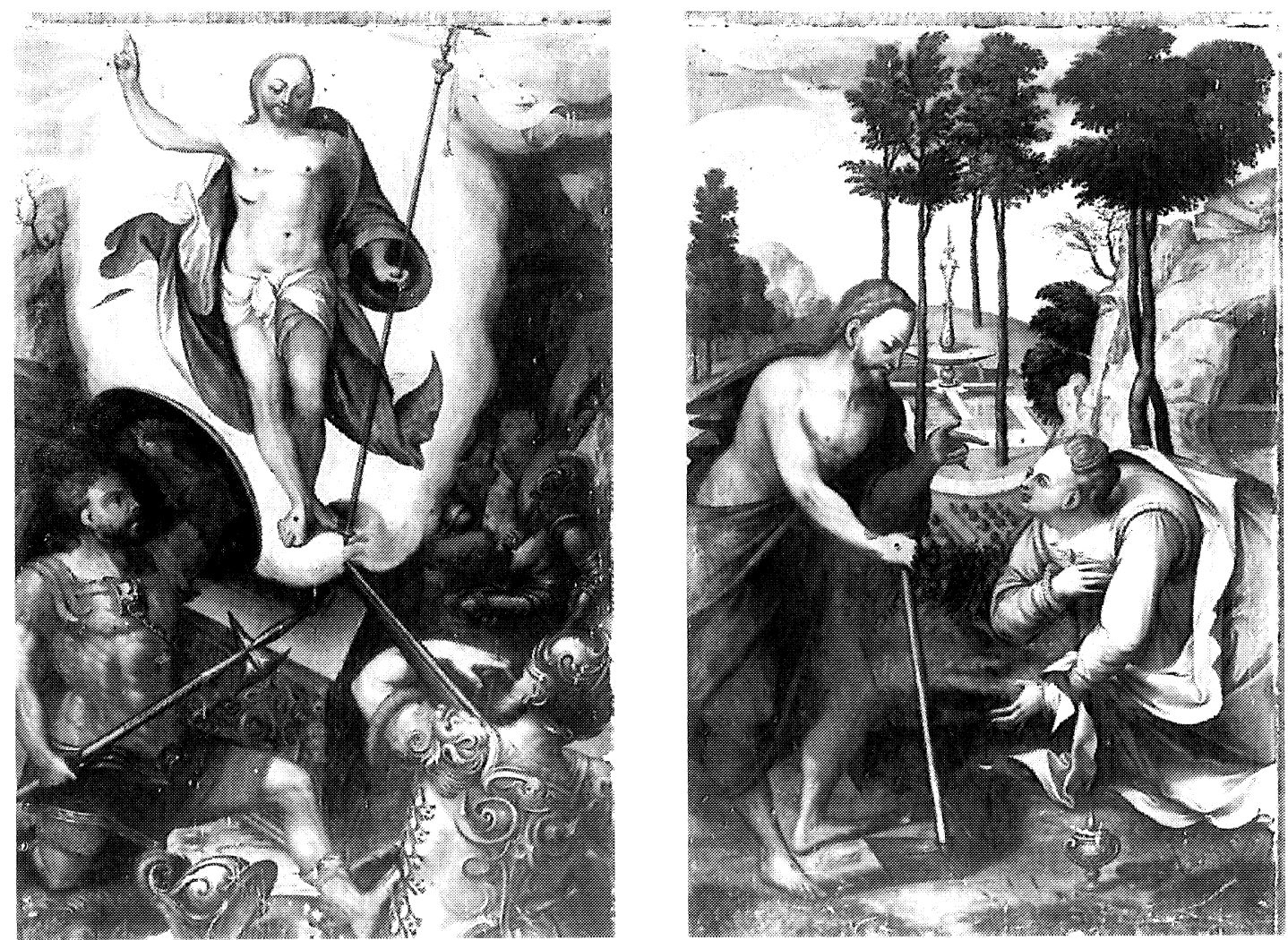

3

Figs. 1-4. Maestro del retablo de Durham, Adoración de los Pastores, Crucifixión, Resurrección, Noli me tangere. Durham, Duke University Museum of Art (Dr. Paul J. Payne). 

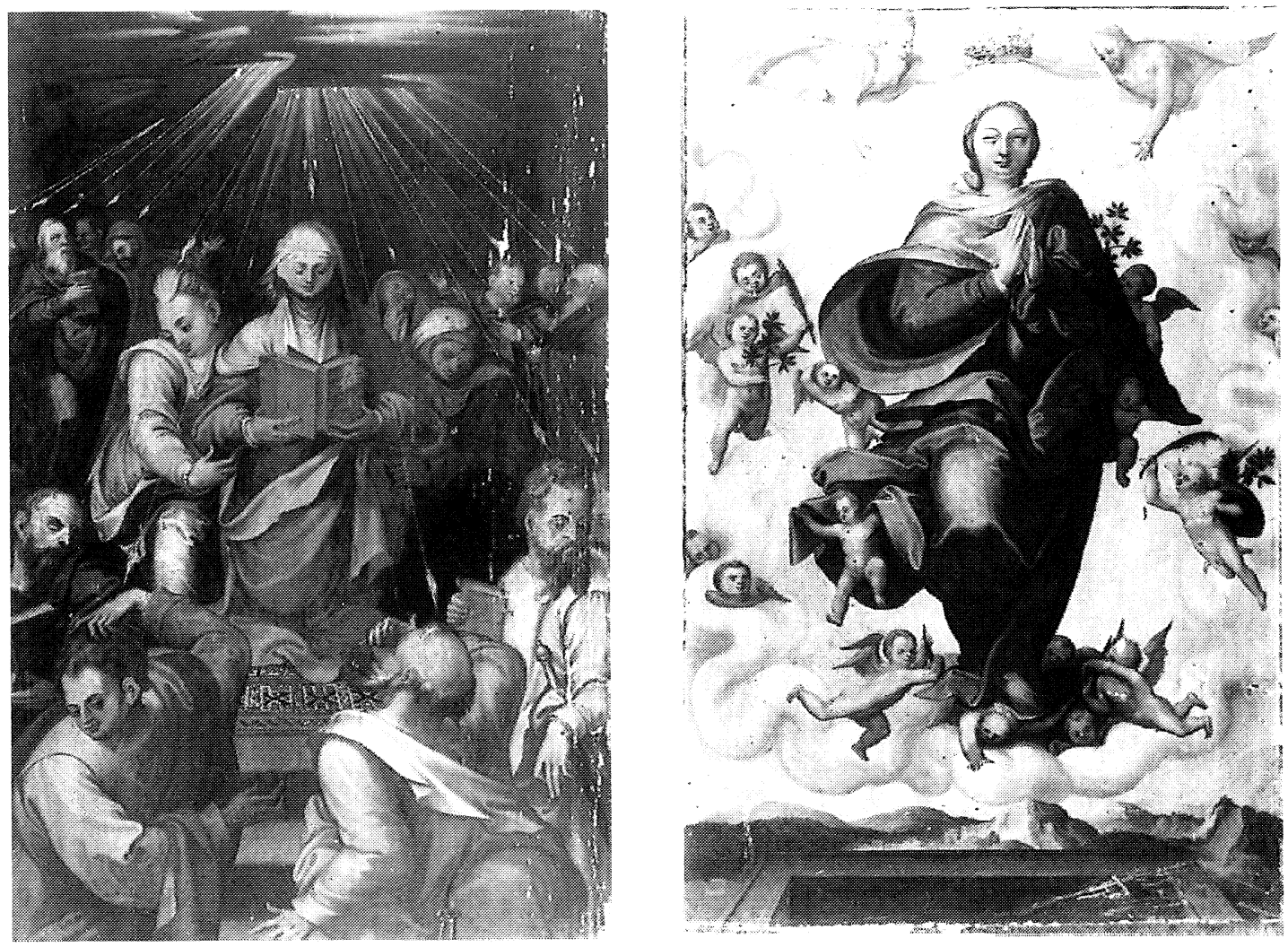

5

6

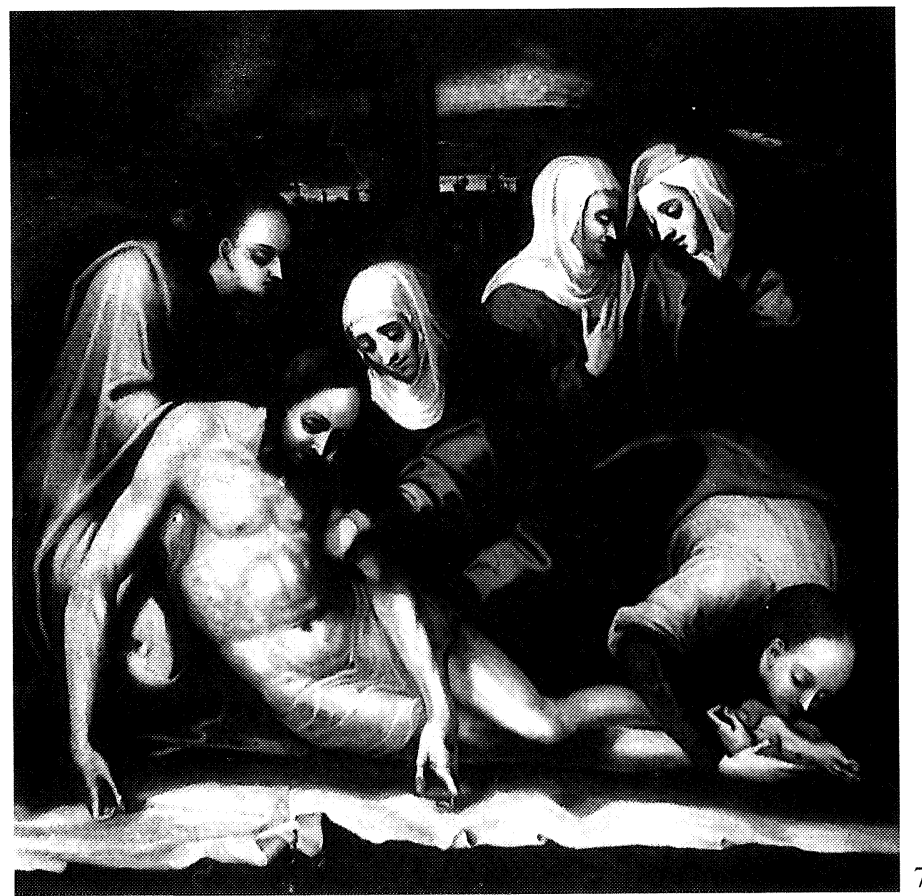

Figs. 5-6. Maestro del retablo de Durham, Venida del Espíritu Santo, Coronación de la Virgen. Durham, Duke University Museum of Art (Dr. Paul J. Payne).

Fig. 7. Maestro del retablo de Durham, Piedad. Madrid, Colección privada. 
En la siguiente escena, la Crucifixión (fig. 2) el modelado del cuerpo de Cristo y las partes a destacar de ropajes y figuras, se resaltan por medio de la luz, consiguiéndose con el claroscuro mayor dramatismo para la escena. La figura de san Juan, de espaldas, con una actitud de pies y manos nada sosegada evoca cierto desasosiego de las composiciones grunwaldianas.

La Resurrección (fig. 3), con los efectos de luz precisos para modelar a los soldados del primer término, vuelve a ser una composición de proporciones y sensibilidad miguelangelesca, con cierto gusto decorativo en los relieves del sepulcro y en las guarniciones de las armaduras.

Sin duda la escena más atractiva es el Noli me tangere (fig. 4). En ella contrasta el ligero, armónico y lineal jardín típico del último renacimiento, con las voluminosas figuras, singularmente la de la Magdalena. Cristo como jardinero con su azada, se le aparece a su discípula predilecta (San Marcos 16,9 y San Juan 14-18). La Magdalena, con corpulentísimo cuerpo y una cabeza, en relación con él, pequeña, se arrodilla ante él, teniendo próximo a ella el simbólico frasco de perfume. Su peinado a base de bucles recogidos por finas trenzas los hallamos en Goltzius hacia el año 1570, fecha que coincide con la del tocado de la Magdalena en la escena de la Venida del Espiritu Santo, en este mismo retablo. En esta última tabla, el concepto de amaneramiento de las figuras, el movimiento de las mismas y los efectos de luz están acordes con lo pintado en estos últimos años del siglo Xvi.

Finalmente en la tabla de la Coronación de la Virgen (fig. 6) desaparecen los efectos de luz siendo el dinamismo de los ángeles y el del manto de la Virgen los protagonistas de la composición, preludiando las Inmaculadas barrocas.

Si nos fijamos en su dependencia de Leyden y Goltzius, tal vez habríamos de pensar en un pintor flamenco, con estancia en Italia, y posteriormente trabajando en Toledo. Como de su estilo sólo hemos localizado una Piedad, (fig. 7), en colección privada madrileña $(83 \times 82 \mathrm{~cm}$ ), con atribución a Correa, cuyos modelos coinciden con los del retablo de Durham, tal vez se trate de un pintor itinerante o de paso por Toledo, al que, de momento, podríamos denominar como Maestro del retablo de Durham.

Isabel Mateo Gómez Dpt. H. ${ }^{\mathrm{a}}$ del Arte, CSIC

\section{EL TEMPLO PARROQUIAL DE LA CAMPANA (SEVILLA): LAS REFORMAS DEL SIGLO XVIII}

Los orígenes de la iglesia parroquial de La Campana debemos situarlos acaso en la primera mitad del siglo Xv cuando se fundó una ermita dedicada a la Virgen de la Consolación, en torno a la cual se apiñaban un conjunto de casas habitadas por trabajadores de los campos del entorno ${ }^{1}$. Ya en la segunda mitad de la misma centuria aparece mencionado el edificio como «la iglesia de La Campana” ', evidenciándose que constituía ya una auténtica fábrica, con sus presbíteros y sus rentas, no dependiendo, pues, del priorato de ermitas.

\footnotetext{
1 Manuel Serrano afirmó que la vieja ermita originaria estaba dedicada a la Virgen del Carmen; sin embargo, desconocemos de dónde extrajo la información y más bien pensamos que fue un error de su autor. Serrano y Ortega, Manuel: Guía de los monumentos históricos y artísticos de los pueblos de la provincia de Sevilla, Sevilla, 1911, p. 59.

2 González Jiménez, Manuel: Catálogo de documentación medieval del Archivo Municipal de Carmona (1475-1504), t. II, Sevilla, Diputación Provincial, 1981, p. 239.
} 